\title{
Epidemiology of viral respiratory infections in a pediatric reference hospital in Central Panama
}

Virginia Núñez-Samudio ${ }^{1,2}$ and Iván Landires ${ }^{1,3,4^{*}}$

\begin{abstract}
Background: Acute respiratory infections (ARIs) are a worldwide public health problem. It is estimated that up to $80 \%$ of cases of ARIs are caused by viruses. In Central America, however, we identified few epidemiologic studies on the main ARI-related viruses in hospitalized children.

Methods: This study retrospectively analyzed the clinical charts of patients ages 29 days to 14 years admitted with diagnoses of ARIs in a pediatric reference hospital in central Panama during 2016. The variables analyzed were age, sex, signs, symptoms, and diagnosis at admission. Samples of patients to whom a viral panel was indicated were analyzed via quantitative polymerase chain reaction, qPCR.

Results: The most common virus was respiratory syncytial virus (RSV; 25.9\%), followed by influenza A virus (10.6\%), rhinovirus (10.6\%), parainfluenza type 3 (PIV-3; 8.2\%) and adenovirus (5.9\%). However, virus detection varied with patient age and season. RSV and Influenza virus were respectively identified mainly during July-November and May-July. All cases of viral co-infection occurred in children < 5-years-old. Both influenza A (H1N1) pdm09 and rhinovirus were detected in all pediatric ages analyzed in this study, unlike RSV and PIV-3, which were only present in children $<5$-years-old.

Conclusions: This study analyzed the epidemiological patterns of different respiratory viruses in pediatric patients with ARI from central Panama and found that the prevalence of the specific respiratory viruses identified varied with season and age. The most common viruses were RSV, influenza A, and rhinovirus. There were no reports of human metapneumovirus associated with ARI, which may be explained by the time and geographic location of the study. Knowledge of the local epidemiology of respiratory viruses in tropical countries is helpful in forecasting the peaks of hospitalizations due to ARIs and may help improve prevention efforts aiming at respiratory disease control in these settings.
\end{abstract}

Keywords: Acute respiratory infections, Central America, Epidemiology, Panama, Pediatrics, Surveillance, Viruses

\footnotetext{
* Correspondence: ilandires@institutodecienciasmedicas.org;

ivanlandires@yahoo.es

${ }^{1}$ Instituto de Ciencias Médicas, PO Box 0710-00043, Las Tablas, Los Santos,

Panama

${ }^{3}$ Centro Regional Universitario de Azuero (CRUA), Universidad de Panamá,

Chitré, Herrera, Panama

Full list of author information is available at the end of the article
}

(c) The Author(s). 2021 Open Access This article is licensed under a Creative Commons Attribution 4.0 International License, which permits use, sharing, adaptation, distribution and reproduction in any medium or format, as long as you give appropriate credit to the original author(s) and the source, provide a link to the Creative Commons licence, and indicate if changes were made. The images or other third party material in this article are included in the article's Creative Commons licence, unless indicated otherwise in a credit line to the material. If material is not included in the article's Creative Commons licence and your intended use is not permitted by statutory regulation or exceeds the permitted use, you will need to obtain permission directly from the copyright holder. To view a copy of this licence, visit http://creativecommons.org/licenses/by/4.0/. The Creative Commons Public Domain Dedication waiver (http://creativecommons.org/publicdomain/zero/1.0/) applies to the data made available in this article, unless otherwise stated in a credit line to the data. 


\section{Background}

Acute respiratory infections (ARIs) constitute a complex group of infections affecting any anatomic site within the respiratory tract. Worldwide, these are a large public health problem, ranking among the top causes of pediatric outpatient and inpatient care [2]. Lower ARIs are considered as one of the top causes of mortality in children < 5-years-old [2-5]. Even though ARIs can be caused by diverse etiologic agents, it is estimated that up to $80 \%$ of cases are caused by viruses $[6,7]$. Globally, the human respiratory syncytial virus (RSV; family Pneumoviridae) is one of the main viruses causing lower ARIs and approximately $45 \%$ of the hospitalizations and deaths in children over 6 months old can be attributed to this virus [3]. Other viruses associated with ARIs are rhinovirus (family Picornaviridae); parainfluenza 1-4 viruses (PIV; family Paramyxoviridae); influenza A, B, and C (family Orthomyxoviridae), adenovirus (family Adenoviridae), and human metapneumovirus (HMPV; family Paramyxoviridae) [8-10].

In Central America, we identified few epidemiologic studies on the main ARI-related viruses in hospitalized children, usually due to diagnostic limitations [11]. Given the availability of vaccines and other preventative measures, the virologic characteristics, and the specific epidemiological behavior in each geographic region, causes of ARIs are dynamic, with some pathogens emerging and others in potential decline. It is noteworthy that among all the vaccines that may prevent pediatric ARIs, Panama's Expanded Immunization Program (EIP) includes conjugated pneumococcal vaccines at ages 2 and 4 months with a booster at 12 months and influenza vaccines starting at age 6 month, at a 4-week interval and then each year until 5 years of age [12]. According to a Pan-American Health Organization's 2019 Report on Immunization in the Americas, Panama had an overall vaccine coverage of $95 \%$ during the first year of life [13].

In Panama, epidemiologic surveillance for influenza and other respiratory viruses is conducted as part of the National Epidemiologic Surveillance System [14]. Thus, with the aim of having a better understanding of the dynamics of ARI-related viruses in hospitalized children in tropical countries, we conducted a retrospective study analyzing the prevalence and characteristics of respiratory viruses detected in hospitalized children with a diagnosis of ARI in the Pediatric ward of a public reference hospital in central Panama.

\section{Methods}

A retrospective epidemiologic study of the prevalence and characteristics of respiratory viruses in patients admitted between January and December 2016 with a diagnosis of ARI was carried out in the Pediatrics ward of the Cecilio Castillero General Hospital (CCGH) which admits patients aged between 29 days and 14 years. $\mathrm{CCGH}$, located in the city of Chitré, province of Herrera, is the main public pediatric reference center among the four central provinces of the Republic of Panama (namely, Herrera, Los Santos, Coclé, and Veraguas).

Demographic and clinical data of the children hospitalized with a diagnosis of ARI during 2016 were abstracted from the Medical Records Department. The variables analyzed were age, sex, signs, symptoms, and the following admission diagnoses from the International Statistical Classification of Diseases and Related Health Problems, 10th Revision (ICD-10) [1]: suspected influenza due to unidentified influenza virus with other respiratory manifestations (J11.1), pneumonia, unspecified organism (J18), acute bronchiolitis (J21) and unspecified asthma with acute exacerbation (J45.901). In case the attending physician ordered a respiratory virus panel, the Hospital Epidemiologic Surveillance Database, a component part of the National Epidemiologic Surveillance System, was also searched for cases matching the name and unique identifier of these patients. The respiratory viruses identified were then included as a study outcome.

To confirm a suspected case of viral ARI at the CCGH under the National Epidemiologic Surveillance System, a nasopharyngeal swab is collected, preserved, and transported to the Central Reference Public Health Laboratory at the Gorgas Memorial Institute for Health Studies in Panama City, Panama. Samples of patients to whom a viral panel was indicated were analyzed via quantitative polymerase chain reaction, $\mathrm{qPCR}$, for the respiratory viruses under national surveillance (influenza $\mathrm{A}$ and $\mathrm{B}$, RSV, HMPV, human rhinovirus, adenovirus, and PIV 1, 2 , and 3) $[14,15]$.

Patient's data were grouped by age in three categories $(<1,1-4$, and 5-14 years). For analyses by sex, we compared absolute number of all age groups of females and males hospitalized with a diagnosis of ARI during the study. Data were captured using MS Excel (Microsoft Corporation; Redmond, WA) spreadsheet and data analyses were conducted using Stata v. 11.0 (StataCorp LLC; College Station, TX). We used Fisher's exact test to compare proportions $(\alpha=0.05)$. The prevalence $(P)$ of viral ARI among patients admitted was calculated using the formula $P=C_{v} / N$, where $C_{v}$ is the number of ARI cases with positive viral panel tests for the specific virus $v$ and $N$ is the number of ARI cases with viral panel samples collected during the study period [16].

The study protocol was reviewed and approved by the Bioethics Committee at the University of Panama (No. CBIUP/328/17).

\section{Results}

During 2016, a total of 217 children were admitted with the diagnosis of ARI to the Pediatrics ward of the CCGH 
Table 1 Relationship between age, sex, and clinical presentation of inpatients with ARI and the proportion of patients with a positive viral panel

\begin{tabular}{|c|c|c|}
\hline Patient characteristics & $\begin{array}{l}\text { All hospitalized patients with } \\
\text { ARI }(N=217)\end{array}$ & $\begin{array}{l}\text { Subgroup of patients tested with qPCR } \\
\text { viral panel }(N=85)\end{array}$ \\
\hline \multicolumn{3}{|l|}{ Age group } \\
\hline$<1$ year & $87(40 \cdot 1 \%)$ & $27(31 \cdot 8 \%)$ \\
\hline $1-4$ years & $103(47 \cdot 5 \%)$ & $41(48 \cdot 2 \%)$ \\
\hline $5-14$ years & $27(12 \cdot 4 \%)$ & $17(20 \cdot 0 \%)$ \\
\hline \multicolumn{3}{|l|}{ Sex } \\
\hline Male & $109(50 \cdot 2 \%)$ & $38(44 \cdot 7 \%)$ \\
\hline Female & $108(49.8 \%)$ & $47(55 \cdot 3 \%)$ \\
\hline \multicolumn{3}{|l|}{ Signs and Symptoms } \\
\hline Fever & $150(69 \cdot 1 \%)$ & $67(78.8 \%)$ \\
\hline Shortness of breath & $149(68 \cdot 7 \%)$ & $50(58 \cdot 8 \%)$ \\
\hline Dry cough & $123(56 \cdot 7 \%)$ & $49(57 \cdot 6 \%)$ \\
\hline Rhinorrhea & $92(42 \cdot 4 \%)$ & $37(43 \cdot 5 \%)$ \\
\hline Productive cough & $43(19.8 \%)$ & $15(17 \cdot 6 \%)$ \\
\hline Vomiting & $34(15 \cdot 7 \%)$ & $13(15 \cdot 3 \%)$ \\
\hline Diarrhea & $19(8.7 \%)$ & $9(11 \cdot 1 \%)$ \\
\hline \multicolumn{3}{|l|}{ Diagnosis at Hospitalization (ICD-10 Code) } \\
\hline $\begin{array}{l}\text { Suspected influenza due to unidentified influenza virus with other } \\
\text { respiratory manifestations (J11.1) }\end{array}$ & $104(47.9 \%)$ & $76(89.4 \%)$ \\
\hline Pneumonia, unspecified organism (J18) & $48(22.1 \%)$ & $2(2.4 \%)$ \\
\hline Acute bronchiolitis (J21) & $35(16.1 \%)$ & 5 (5.9\%) \\
\hline Unspecified asthma with acute exacerbation (J45.901) & $30(13.8 \%)$ & $2(2.4 \%)$ \\
\hline
\end{tabular}

Abbreviations: $A R I$ acute respiratory infection, ICD-10 International Statistical Classification of Diseases and Related Health Problems, 10 th Revision, influenza $A$ influenza A (H1N1) pdm09 virus, PIV 3 parainfluenza type 3 virus, $R S V$ respiratory syncytial virus, qPCR quantitative polymerase chain reaction

(Table 1). Among the 217 children admitted with the diagnosis of ARI, 109 (50.2\%) were male and 108 (49.8\%) were female $(P=0.93)$ and $30 \%$ lived in rural areas while $70 \%$ lived in urban areas. One hundred and sixty-seven (77\%; 95\% CI: 71-80\%) cases were admitted between June and August; and 190 (87\%; 95\% CI: 83-91\%) were $<5$-years-old. Nineteen (8.7\%) patients presented with comorbidities, the most important of which was asthma $(12 / 19)$. Other comorbidities included sickle-cell anemia $(3 / 19)$, cerebral palsy $(2 / 19)$, prematurity $(1 / 19)$, and laringotracheomalacia (1/19).

The largest number of patients hospitalized for ARIs presented with fever (69.1\%), shortness of breath (68.7\%) and dry cough $(56.7 \%)$ as the most frequent symptoms. The main cause of hospitalization was suspected influenza due to unidentified influenza virus with other respiratory manifestations (Table 1). Among all patients under 5 years of age, half $(49.5 \%)$ had received an influenza vaccine that year.

Among all patients admitted with a diagnosis of ARI, 85 (39\%; 95\% CI: 33-46) had the epidemiologic surveillance qPCR respiratory virus laboratory panel. Among them, 47 (55\%; 95\% CI: 44-66) were males and 38 (45\%;
95\% CI: 34-55) females. Seventy-six (89\%; 95\% CI: $83-$ 96) of the patients tested with qPCR viral panel were admitted with the diagnosis of suspected influenza due to unidentified influenza virus with other respiratory manifestations while nine were admitted with the diagnoses of acute bronchiolitis $(n=5)$, pneumonia $(n=2)$, and asthma crisis $(n=2)$. The 85 samples analyzed were from patients across all age groups: < 1 year $(n=27), 1-4$ years $(n=41)$, and $5-14$ years $(n=17)$. Positive results were obtained for the viruses under epidemiologic surveillance in $56(66 \%$; $95 \%$ CI: $55-76 \%)$ of the 85 cases, while 29 (34\%) samples were negative. The test positivity proportions for viruses identified across all age groups were $25.9 \%$ for RSV, $10.6 \%$ for influenza A (H1N1) pdm09, $10.6 \%$ for rhinovirus, $8.2 \%$ for PIV-3, and $5.9 \%$ for adenovirus. No infections by HMPV were detected. The test positivity proportions for viral co-infections was $4.7 \%$ and it was confirmed in four samples analyzed for children < 5-years. All four co-infections included the PIV-3; three were co-infections with RSV and one with adenovirus. In the group of patients $<1$-year-old there was an $85.2 \%$ positivity proportion, while this number was $65.6 \%$ among the 1 - to 4 -year-olds group and $35.3 \%$ 
among the 5- to 14-year-olds. The variation of positivity proportions of viruses detected among the three age groups was statistically significant $(P=0.003)$. The viruses most frequently detected in the group of patients $<1$ year-old were RSV ( $n=13)$, influenza A $(n=3)$, PIV 3 ( $n=$ $3)$, rhinovirus $(n=2)$, and co-infection with two viruses $(n=2)$. In the group of patients $1-4$ years of age, we observed RSV $(n=9)$, PIV $3(n=4)$, adenovirus $(n=5)$, rhinovirus $(n=4)$, influenza A $(n=3)$, and co-infection with two viruses $(n=2)$. The $5-14-$ years group had only tested positive for influenza $\mathrm{A}$ and rhinovirus ( $n=3$ each) (Fig. 1). Comparison of the RSV proportions between the three age groups showed a statistically significantly difference $(P=0.02)$.

Regarding the seasonal detection of respiratory viruses, influenza A (H1N1) pdm09 peaked in June, while RSV peaked in August (Fig. 2). Both influenza A (H1N1) pdm09 and rhinovirus were detected in all pediatric ages analyzed in this study, unlike RSV and PIV-3, which were only present in children $<5$-years-old.

\section{Discussion}

This study describes the epidemiology of respiratory viruses in children admitted with the diagnosis of ARI in a reference hospital in central Panama. ARIs, at $45 \%$ of total admissions, constituted one of the top diagnoses among hospitalized children < 14-years old-especially among children < 5-years-old-without overall statistically significant differences by sex [3]. Earlier studies with inpatients in the Central American region showed that respiratory viruses are responsible for $52.6 \%$ of all the ARI cases, affecting mostly children < 5-years-old [11].

A virus was identified in about half (54.1\%) of the samples analyzed. Studies conducted in hospitalized patients have evidenced positivity rates between 36 and 85\% [6, 17]. We observed that the proportions of the specific respiratory viruses identified varied by age and month of the year (Figs. 1 and 2, respectively). The overall prevalence of RSV was $25.9 \%$, but it was higher (48\%) for children $<1$-year-old. These findings resemble those from a study in Guatemala, where the prevalence of RSV in hospitalized children was $26.4 \%$, and it was higher (71.8\%) for children < 1-year-old [11]. The relatively higher prevalence of RSV as a causative agent of ARI in hospitalized children < 5-years-old has also been documented [5].

Influenza A (H1N1) pdm09 and rhinovirus each had a prevalence of $10.6 \%$. Both viruses were detected in the three age groups, unlike RSV and PIV-3, which were only present in children < 5-years-old. Previous studies in low- and middle-income countries have also described these viruses as relatively common among patients hospitalized with ARI $[17,18]$.

The prevalence of viral co-infection was 5\%. All the co-infections occurred in children $<5$-years-old and all of them occurred with PIV-3. Previous studies detected co-infections at similar rates, mostly due to two viruses $(82.1 \%)$, with a high percentage of positive results in younger children, probably due to low viral elimination by the developing immune system $[8,11]$. The proportion of children with co-infections in this study is similar to other studies in Central America [19].

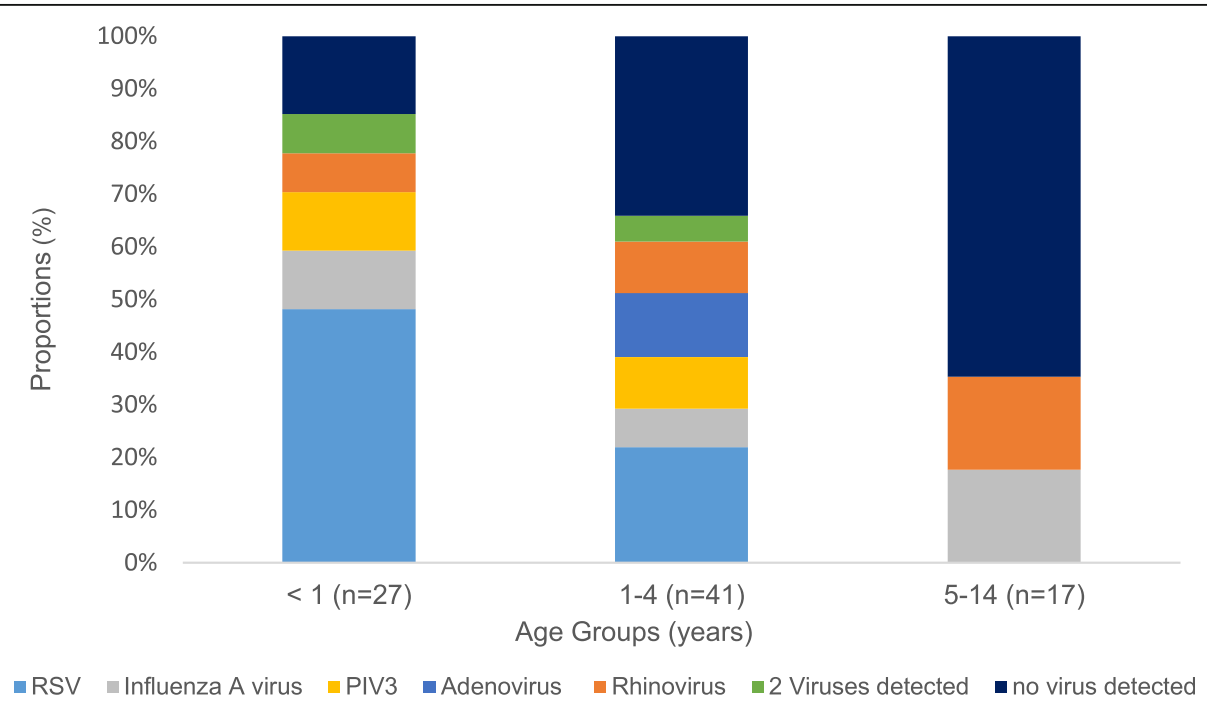

Fig. 1 Frequency of viral pathogens detected on nasopharyngeal/oropharyngeal swab by age group. The main virus detected in the samples analyzed for the groups of < 1 year and 1-4 years was the RSV, detected in 48 and 22\% respectively. In the group of 5-14 years of age, Influenza A and Rhinovirus were detected, accounting for 35\% of the samples analyzed. Abbreviations: Influenza A virus,: influenza A (H1N1) pdm09; PIV, parainfluenza type 3 virus; RSV, respiratory syncytial virus 


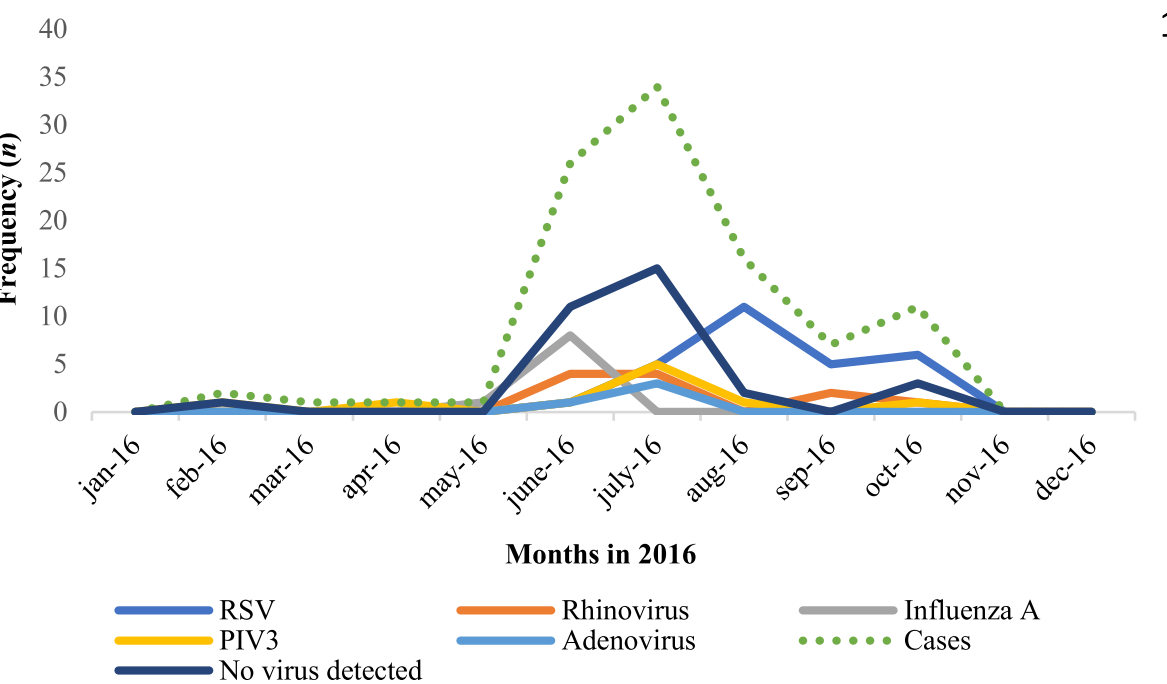

Fig. 2 Detection of respiratory viruses by month of the year 2016. This figure shows that from May to November is the period where the majority of hospitalizations for ARIs occur. Influenza A peaked from May to July while RSV peaked from July to November. The ARIs for adenovirus, PIV-3, and rhinovirus were also increasing in smaller proportion from May to November. Abbreviations: ARIs: Acute respiratory infections, Influenza A virus, influenza A (H1N1) pdm09; PIV, parainfluenza type 3 virus; RSV, respiratory syncytial virus. Case, total number of cases with acute respiratory infection where a viral panel was assessed

The most frequent viruses identified were RSV (25.9\%), influenza A (10.6\%), and rhinovirus (10.6\%). We identified RSV from July-November, with the peak in August, while influenza virus was identified in May-July, with the peak in June. This variation is in accordance with that reported from other tropical countries [16]. Panama has a dry, tropical climate [20]. In Central America, the annual precipitation cycle can be approximately divided in a dry season from December to April and in a rainy season from May to November [21]. Increased precipitation and humidity might be factors in the transmission of respiratory viruses [22] and it has been hypothesized that tropical rainy seasons may encourage the transmissibility of RSV more than that of influenza [21].

Although, HMPV was not reported in this study, it is a leading cause of ARIs in other studies from Central America [19, 23]. Metapneumovirus is interesting, as the virus is associated with high morbidity in mainly highincome countries $[24,25]$ but also was recently found in high numbers in the PERCH multi-center study of pneumonia in low-income countries [26]. Panama included HMPV surveillance in 2010 as part of the National Epidemiologic Surveillance System. A previous study [27] described a HMPV frequency among $\leq 5$-year-olds hospitalized patients with ARI of $1.3 \%$ in 2011 and $13.9 \%$ in 2012, which may suggest important fluctuations over time. We did not detect HMPV in hospitalized children with ARI in 2016. A possible explanation is variability over time and geographic location of respiratory pathogens.
Vaccination against influenza was included in Panama's Broadened Immunization Program from 2010 and it is administered every year starting in April to children between 6 and 35 months of age and any person, regardless of their age, who presents with a chronic health condition [28]. We have found that at the time of their admission, an important number of children were vaccinated against influenza (49.5\%), which could have contributed to the lower frequency of cases of ARI due to influenza A (H1N1) pdm09.

This study used the WHO criteria to classify ARIs [29] and included patients under 5 years of age hospitalized with ARI. Thus, an important limitation is the limited generalizability to children with ARI who do not require hospitalization. According to the WHO classification, although the group of patients older than 5 years was hospitalized, their condition could not be classified as severe ARI. This limitation aside, this study provides important information in the epidemilogic behavior of ARIs in a central american tropical country.

\section{Conclusions}

This study analyzed the epidemiological patterns of different respiratory viruses in pediatric patients with ARI from central Panama and found that the prevalence of the specific respiratory viruses varied with season and age. In addition RSV, influenza $\mathrm{A}$ virus and rhinovirus are the most common viruses. Knowledge of the local epidemiology of tropical climate regions is helpful in forecasting the peaks of respiratory viruses associated with hospitalization due to ARI. This in turn could translate into improved prevention efforts aiming at respiratory disease control, including hospital measures to improve infection control [30]. 


\section{Abbreviations}

ARIs: Acute respiratory infections; CCGH: Cecilio Castillero General Hospital; EIP: Expanded Immunizatio Program; ICD-10: International Statistical Classification of Diseases and Related Health Problems, 10th Revision [1]; PIV: Parainfluenza virus; RSV: Respiratory syncytial virus; qPCR: quantitative polymerase chain reaction

\section{Acknowledgements}

The authors would like to acknowledge Humberto López Castillo, MD, PhD $\mathrm{CPH}, \mathrm{CMI}$, for his review of the manuscript. The authors are particularly grateful for the assistance given by José Armando Núñez, BSc. Dr. Iván Landires is member of the Sistema Nacional de Investigación (SNI), which is supported by the Secretaría Nacional de Ciencia, Tecnología e Innovación (SENACYT), Panamá

\section{Authors' contributions}

VN-S and IL contributed equally to study conceptualization and design, data acquisition and analysis, interpretation, manuscript drafting and revision, and approved the final version for publication.

\section{Funding}

No funding was received for this study.

\section{Availability of data and materials}

The datasets used and analyzed are available from the corresponding author on reasonable request.

\section{Ethics approval and consent to participate}

The study protocol was approved by the Bioethics Committee of the University of Panama (No. CBIUP/328/17). No further administrative permissions were needed to access the raw data used in this study. The data used in this study were anonymized before use.

\section{Consent for publication}

Not applicable.

\section{Competing interests}

The authors declare that they have no competing interests.

\section{Author details}

${ }^{1}$ Instituto de Ciencias Médicas, PO Box 0710-00043, Las Tablas, Los Santos, Panama. ${ }^{2}$ Sección de Epidemiología, Departamento de Salud Pública, Región de Salud de Herrera, Ministry of Health, Chitré, Panama. ${ }^{3}$ Centro Regional Universitario de Azuero (CRUA), Universidad de Panamá, Chitré, Herrera, Panama. ${ }^{4}$ Hospital Joaquín Pablo Franco Sayas, Región de Salud de Los Santos, Ministry of Health, Las Tablas, Panama.

\section{Received: 3 January 2020 Accepted: 18 December 2020} Published online: 09 January 2021

\section{References}

1. World Health Organization. International Statistical Classification of Diseases and Related Health Problems, 10th Revision. Available from: https://icd.who. int/browse10/2019/en. Accesed 24 Oct 2020.

2. Liu L, Oza S, Hogan D, Chu Y, Perin J, Zhu J, et al. Global, regional, and national causes of under-5 mortality in 2000-15: an updated systematic analysis with implications for the sustainable development goals. Lancet. 2016:388(10063):3027-

3. Shi T, McAllister DA, O'Brien KL, Simoes EAF, Madhi SA, Gessner BD, et al. Global, regional, and national disease burden estimates of acute lower respiratory infections due to respiratory syncytial virus in young children in 2015: a systematic review and modelling study. Lancet. 2017;390(10098): 946-58.

4. Juvén T, Mertsola J, Waris M, Leinonen M, Meurman O, Roivainen M, et al. Etiology of community-acquired pneumonia in 254 hospitalized children. Pediatr Infect Dis J. 2000;19(4):293-8.

5. Nascimento-Carvalho CM, Ribeiro CT, Cardoso MR, Barral A, Araújo-Neto CA Oliveira JR, et al. The role of respiratory viral infections among children hospitalized for community-acquired pneumonia in a developing country. Pediatr Infect Dis J. 2008;27(10):9399-41.
6. Fernandes-Matano L, Monroy-Muñoz IE, Angeles-Martínez J, SarquizMartinez B, Palomec-Nava ID, Pardavé-Alejandre HD, et al. Prevalence of non-influenza respiratory viruses in acute respiratory infection cases in Mexico. PLoS One. 2017;12(5):e0176298.

7. Shay DK, Holman RC, Newman RD, Liu LL, Stout JW, Anderson LJ. Bronchiolitis-associated hospitalizations among US children, 1980-1996. JAMA. 1999;282(15):1440-6.

8. van den Hoogen BG, de Jong JC, Groen J, Kuiken T, de Groot R, Fouchier RA, et al. A newly discovered human pneumovirus isolated from young children with respiratory tract disease. Nat Med. 2001;7(6):719-24.

9. Allander T, Tammi MT, Eriksson M, Bjerkner A, Tiveljung-Lindell A, Andersson $B$, et al. Cloning of a human parvovirus by molecular screening of respiratory tract samples. Proc Natl Acad Sci U S A. 2005;102(36):12891-986.

10. Woo PC, Lau SK, Chu CM, Chan KH, Tsoi HW, Huang Y, et al. Characterization and complete genome sequence of a novel coronavirus, coronavirus HKU1, from patients with pneumonia. J Virol. 2005;79(2):884-95.

11. Verani JR, McCracken J, Arvelo W, Estevez A, Lopez MR, Reyes L, et al. Surveillance for hospitalized acute respiratory infection in Guatemala. PLoS One. 2013;8(12):e83600.

12. Ministerio de Salud de Panamá. (2017). Esquema Nacional de Vacunación. Available from: http://minsa.b-cdn.net/sites/default/files/programas/ esquema_nacional_de_vacunacion_2017_1.pdf.

13. Pan-American Health Organization (2019). Inmunización en las Américas. Available from: https://www.paho.org/es/documentos/inmunizacionamericas-resumen-2019.

14. Ministerio de Salud de Panamá (2018). Guía Nacional de Epidemiología. Available from: http://www.minsa.gob.pa/sites/default/files/publicaciongeneral/documento_guia_nacional_de_ve_13-12-18.pdf.

15. Tulloch F, Correa R, Guerrero G, Samaniego R, Garcia M, Pascale JM, et al. Profile of the first case hospitalized due to influenza a (H1N1) in Panama City, Panama. May-June 2009. J Infect Dev Ctries. 2009;3(11):811-6.

16. Nolan T, Borja-Tabora C, Lopez P, Weckx L, Ulloa-Gutierrez R, Lazcano-Ponce $E$, et al. Prevalence and incidence of respiratory syncytial virus and other respiratory viral infections in children aged 6 months to 10 years with influenza-like illness enrolled in a randomized trial. Clin Infect Dis. 2015; 60(11):e80-9.

17. da Silva ER, Pitrez MC, Arruda E, Mattiello R, Sarria EE, de Paula FE, et al. Severe lower respiratory tract infection in infants and toddlers from a nonaffluent population: viral etiology and co-detection as risk factors. BMC Infect Dis. 2013;13:41.

18. Hasan R, Rhodes J, Thamthitiwat S, Olsen SJ, Prapasiri P, Naorat S, et al. Incidence and etiology of acute lower respiratory tract infections in hospitalized children younger than 5 years in rural Thailand. Pediatr Infect Dis J. 2014;33(2):e45-52.

19. Schlaudecker EP, Heck JP, Macintyre ET, et al. Etiology and seasonality of viral respiratory infections in rural Honduran children. Pediatr Infect Dis J. 2012;31(11):1113-8.

20. Murphy MJ Jr, Georgakakos KP, Shamir E. Climatological analysis of December rainfall in the Panama Canal watershed. Int J Climatol. 2014;34(2): 403-15

21. Bloom-Feshbach K, Alonso WJ, Charu V, Tamerius J, Simonsen L, Miller MA, et al. Latitudinal variations in seasonal activity of influenza and respiratory syncytial virus (RSV): a global comparative review. PLoS One. 2013;8(2): e54445.

22. Paynter S. Humidity and respiratory virus transmission in tropical and temperate settings. Epidemiol Infect. 2015;143(6):1110-8.

23. McCracken JP, Arvelo W, Ortíz J, et al. Comparative epidemiology of human metapneumovirus- and respiratory syncytial virus-associated hospitalizations in Guatemala. Influenza Other Respir Viruses. 2014;8(4):414-21.

24. Rhedin S, Lindstrand A, Hjelmgren A, et al. Respiratory viruses associated with community-acquired pneumonia in children: matched case-control study. Thorax. 2015;70(9):847-53.

25. Jain S, Self WH, Wunderink RG, et al. Community-acquired pneumonia requiring hospitalization among U.S. adults. N Engl J Med. 2015;373(5):415-27.

26. Pneumonia Etiology Research for Child Health (PERCH) Study Group. Causes of severe pneumonia requiring hospital admission in children without HIV infection from Africa and Asia: the PERCH multi-country case-control study. Lancet. 2019;394(10200):757-79.

27. Ábrego LE, Mirazo S, Delfraro A, et al. Genotypes of human metapneumovirus circulating during 2010-2012 in children from Panama. J Med Virol. 2018;90(3):604-8. 
28. Ministerio de salud de Panamá. Programa Ampliado de Inmunización: Manual de normas y procedimientos, (2012). Available from: http://www. minsa.gob.pa/sites/default/files/programas/folleto_normas.pdf.

29. PAHO. PAHO-CDC: Generic Protocol for Influenza Surveillance. Washington DC; 2006. Available from: http://www.paho.org/english/ad/dpc/cd/flusnlgpis.pdf.

30. Nascimento-Carvalho CM, Cardoso MR, Barral A, Araújo-Neto CA, Oliveira JR, Sobral LS, et al. Seasonal patterns of viral and bacterial infections among children hospitalized with community-acquired pneumonia in a tropical region. Scand J Infect Dis. 2010;42(11-12):839-44.

\section{Publisher's Note}

Springer Nature remains neutral with regard to jurisdictional claims in published maps and institutional affiliations.

Ready to submit your research? Choose BMC and benefit from:

- fast, convenient online submission

- thorough peer review by experienced researchers in your field

- rapid publication on acceptance

- support for research data, including large and complex data types

- gold Open Access which fosters wider collaboration and increased citations

- maximum visibility for your research: over $100 \mathrm{M}$ website views per year

At BMC, research is always in progress.

Learn more biomedcentral.com/submissions 